\title{
A LINEAR TIME-INVARIANT MODEL FOR A VECTOR- CONTROLLED TWO-PHASE STEPPING MOTOR
}

\author{
S. Derammelaere ${ }^{1,2}$, B. Vervisch ${ }^{1,2}$, F. De Belie ${ }^{2}$, J. Cottyn ${ }^{1}$, G. Van den Abeele ${ }^{3}$, P. Cox ${ }^{4}$, \\ K. Stockman ${ }^{1,2}$, L. Vandevelde ${ }^{2}$ \\ ${ }^{1}$ Technical University College of West-Flanders, Graaf Karel de Goedelaan 5, Kortrijk 8500, Belgium \\ ${ }^{2}$ Department of Electrical Energy, Systems and Automation, Ghent University, Gent 9000, Belgium \\ ${ }^{3}$ PsiControl Mechatronics, K. Steverlyncklaan 13, Ieper 8900, Belgium \\ ${ }^{4}$ ON Semiconductor, Westerring 15, Oudenaarde 9700, Belgium
}

Keywords: Stepping Motor, Vector Control, Modelling

\begin{abstract}
Recent research on stepping motors concerns intelligent motion control algorithms such as sensorless vector control. Sensorless control is commonly based on a motor model. For stepping motors, this model is highly non-linear, resulting in high computational cost. In this paper it is shown that the motor model can be transformed into a linear model, if the stepping motor is controlled by a vector-control algorithm. The linear model is validated by simulations and sensitivity analysis proves the robustness of the model.
\end{abstract}

\section{Introduction}

Stepping motors are commonly driven in open loop. The fact that an expensive sensor is not needed makes them very interesting for industrial and domestic applications. However, open loop control results in torque and speed ripples, noisy operation, resonance frequencies and positioning errors. Closed-loop control methods, such as vector control, can handle these problems and drive the stepping motor in a more efficient and dynamic way [1]. To apply these methods, rotor position information is needed. Thanks to recent research on permanent magnet synchronous machines and switched reluctance motors, position information can be gained without using a sensor. In this way, it is possible to have both advantages of open-loop sensorless control and closed-loop vector control principles.

Sensorless control is commonly based on a model of the machine. In [2], the sensorless control algorithm for stepping motors is based on a state space model in the stator reference frame, which is highly nonlinear. Such a model results in a complex sensorless algorithm and a high computational cost.

In this paper, a linear model for a vector-controlled two-phase hybrid stepping motor is proposed. Based on the vectorcontrol principles, the position dependence of certain model parameters can be eliminated, which results in a linear model, as shown in [3] for a PMSM. In this way, simpler observers can be applied, which strongly reduce the computational cost [4].

Simulations on a two-phase hybrid stepping motor are conducted to validate the model. The simulation set-up is also used to perform a sensitivity analysis which proves the robustness of the linear model.

\section{Stepping motor torque generation}

The principle of a two-phase hybrid stepper motor is illustrated in Fig. 1 [5]. The stator is equipped with windings while the multi-toothed rotor is magnetized by means of permanent magnets.

The rotor tooth is attracted by the excited stator phase. Fig. 2 shows the static torque-rotor position curves. The solid curve illustrates the torque-position relation for an excited phase A. For a given load torque $T_{\text {load, }}$, a stable operating point $\mathrm{p}$ is reached. The dotted line illustrates the torque when phase $B$ is excited and the excitation of phase $\mathrm{A}$ is removed. For the same load torque $T_{\text {load, }}$ the rotor rotates until a new equilibrium point $\mathrm{q}$ is reached. This is an uncontrolled movement resulting in possible oscillations and noisy operation.

As shown in Fig. 2, for an excited phase A, the maximum torque, generated by the dc current in phase A, is available at $\theta_{\text {electrical }}=-90^{\circ}$. For the load torque in Fig. 2 , the motor is used in position $\mathrm{p}$. In this case, the maximum torque, related to the applied current is not required to hold the load. The torque/current ratio is not optimal resulting in a low efficiency. A vector control algorithm will optimize the current/torque ratio. This advanced control algorithm will result in a more controlled movement, reducing the oscillations.

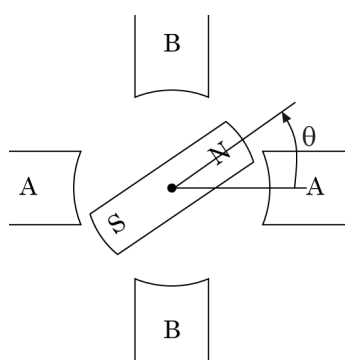

Figure 1: Crosssection of a hybrid two-phase stepping motor

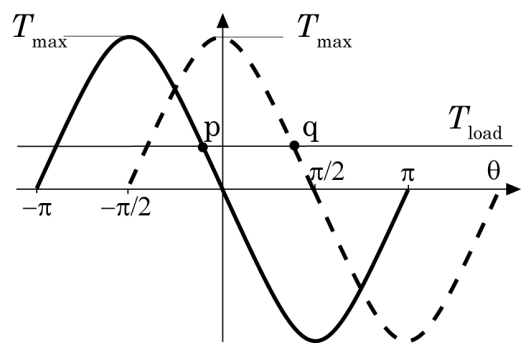

Figure 2: Torque-rotor position curves 


\section{Stepping motor model}

The model of a two phase stepping motor is based on the electrical equations of the phases:

$$
\begin{aligned}
& u_{\mathrm{a}}=L_{\mathrm{a}} \cdot \frac{\mathrm{d}_{i_{\mathrm{a}}}}{\mathrm{dt}}+R_{\mathrm{a}} \cdot i_{\mathrm{a}}+e_{\mathrm{a}} \\
& u_{\mathrm{b}}=L_{\mathrm{b}} \cdot \frac{\mathrm{d}_{i_{\mathrm{b}}}}{\mathrm{dt}}+R_{\mathrm{b}} \cdot i_{\mathrm{b}}+e_{\mathrm{b}}
\end{aligned}
$$

The voltages $u_{\mathrm{a}}$ and $u_{\mathrm{b}}$ are used to control the current while the back emfs per phase depend on the position and speed:

$$
\begin{aligned}
& e_{\mathrm{a}}=C_{\mathrm{emfa}}(\theta) \cdot \omega \\
& e_{\mathrm{b}}=C_{\mathrm{emfb}}(\theta) \cdot \omega
\end{aligned}
$$

The torque produced per phase also depends on the current and rotor position.

$$
T_{\text {motor }}=T_{\mathrm{a}}+T_{\mathrm{b}}=C_{T \mathrm{a}}(\theta) \cdot i_{\mathrm{a}}+C_{T \mathrm{~b}}(\theta) \cdot i_{\mathrm{b}}
$$

In this way, the torque delivered by the motor is obtained as a function of the rotor position. Finally, the equation of motion is given by:

$$
T=T_{\text {load }}+f_{\mathrm{V}} \cdot \omega+J \cdot \frac{\mathrm{d} \omega}{\mathrm{d} t}
$$

This model is higly nonlinear due to the position dependence of the torque -and back-emf constants as illustrated in Fig. 3.

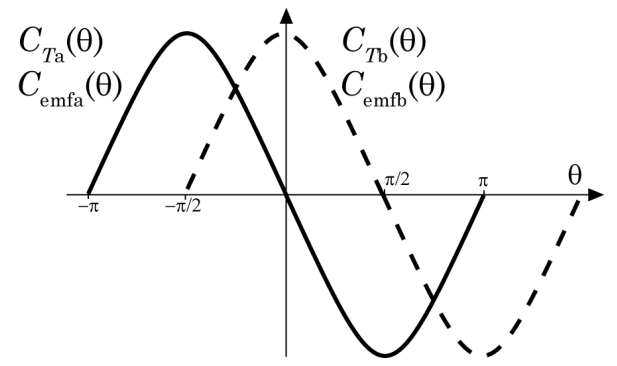

Figure 3: torque and back-emf constant position dependence

\section{Vector control principle}

Fig. 4 illustrates the vector control principle. The flux vector $\overrightarrow{\Psi_{\mathrm{R}}}$ is fixed to the permanent magnet rotor. For the vector control algorithm, the two phases can be excited simultaneously. The currents in phase $\mathrm{a}$ and $\mathrm{b}$ will then result in the stator current vector $\overrightarrow{i_{\mathrm{s}}}$.

The load angle $\delta$ between the stator current vector $\overrightarrow{i_{\mathrm{s}}}$ and the rotor flux vector $\overrightarrow{\Psi_{\mathrm{R}}}$ influences the torque generation as shown in Fig. 2. When neglecting reluctance effects the generated torque can then be noted as:

$$
T_{\text {motor }}=C_{T} \cdot i_{\mathrm{s}} \cdot \sin (\delta)
$$

According to equation (5), the torque generation is optimal when $\delta$ equals $90^{\circ}$, and the generated torque is proportional with the stator current amplitude.

The vector control algorithm is then illustrated in Fig. 5. The set point currents $i_{\mathrm{a}}{ }^{*}$ and $i_{\mathrm{b}}{ }^{*}$ are computed in order to have a load angle $\delta$ close to 90 degrees (a safety margin is necessary for a good dynamical behavior) and the current amplitude $i_{\mathrm{s}}$ results in the necessary torque.

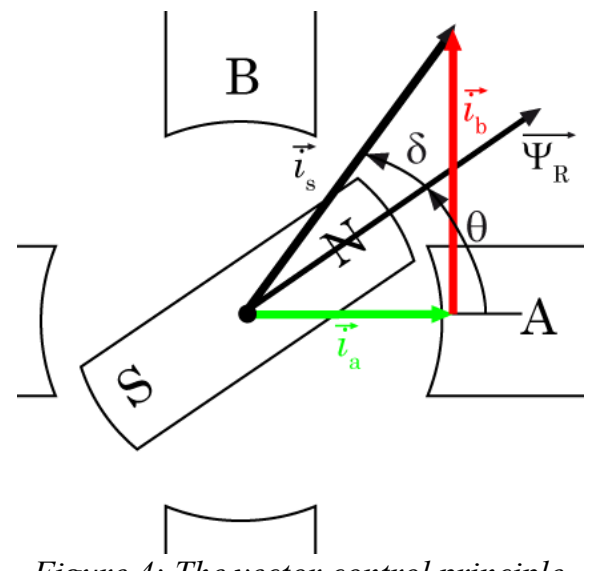

Figure 4: The vector control principle

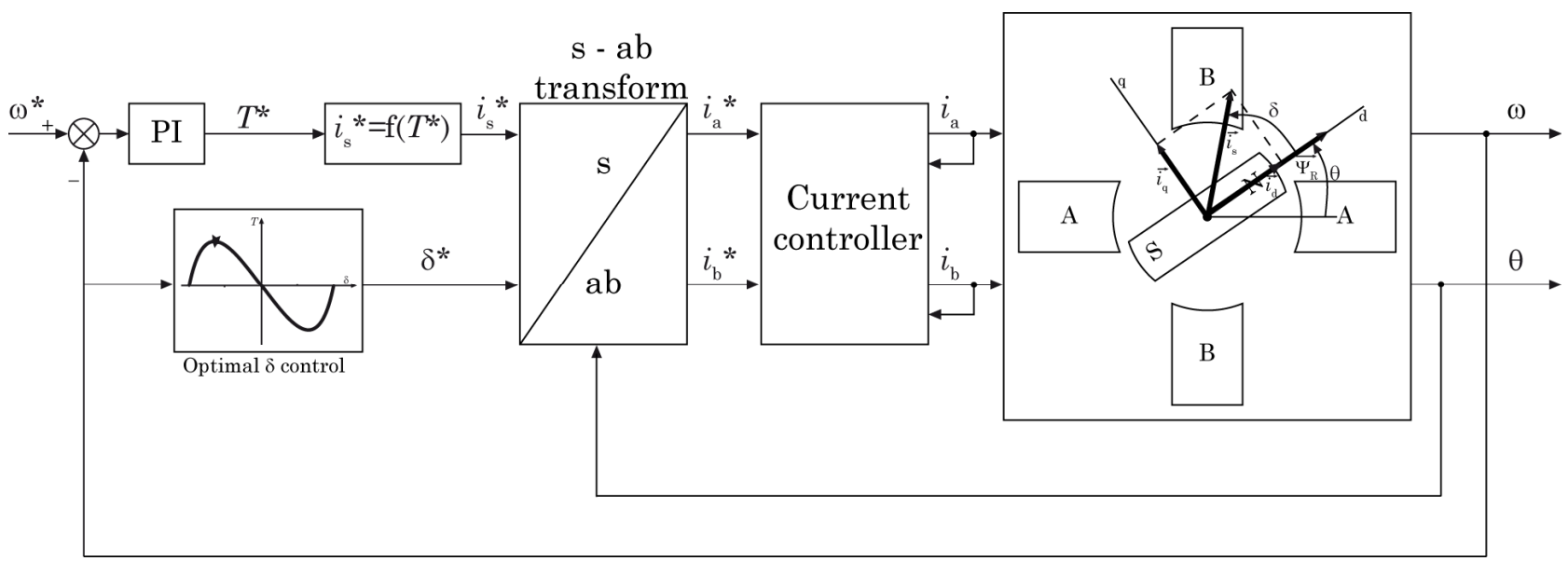

Figure 5: Vector control algorithm 


$$
\left\{\begin{array}{l}
L_{\mathrm{a}} \frac{\mathrm{d} i_{\mathrm{a}}}{\mathrm{d} t}=-R_{\mathrm{a}} \cdot i_{\mathrm{a}}-C_{\text {emfa }}(\theta) \cdot \omega+u_{\mathrm{a}} \\
L_{\mathrm{b}} \frac{\mathrm{d} i_{\mathrm{b}}}{\mathrm{d} t}=-R_{\mathrm{b}} \cdot i_{\mathrm{b}}-C_{\mathrm{emfb}}(\theta) \cdot \omega+u_{\mathrm{b}} \\
J \cdot \frac{\mathrm{d} \omega}{\mathrm{d} t}=C_{T \mathrm{a}}(\theta) \cdot i_{\mathrm{a}}+C_{T \mathrm{~b}}(\theta) \cdot i_{\mathrm{b}}-T_{\text {load }}
\end{array}\right.
$$

Nonlinear Model

$\left\{\begin{array}{c}i_{\mathrm{s}}=\cos (\delta+\theta) \cdot i_{\mathrm{a}}+\sin (\delta+\theta) \cdot i_{\mathrm{b}} \\ v_{\mathrm{s}}=\cos (\delta+\theta) \cdot v_{\mathrm{a}}+\sin (\delta+\theta) \cdot v_{\mathrm{b}} \\ e_{\mathrm{s}}=\cos (\delta+\theta) \cdot e_{\mathrm{a}}+\sin (\delta+\theta) \cdot e_{\mathrm{b}} \\ R_{\mathrm{s}}=\cos ^{2}(\delta+\theta) \cdot R_{\mathrm{a}}+\sin ^{2}(\delta+\theta) \cdot R_{\mathrm{b}} \\ L_{\mathrm{s}}=\cos ^{2}(\delta+\theta) \cdot L_{\mathrm{a}}+\sin ^{2}(\delta+\theta) \cdot L_{\mathrm{b}}\end{array}\right.$

Transformation

$$
\left\{\begin{array}{l}
\frac{\mathrm{d} i_{\mathrm{s}}}{\mathrm{d} t}=\frac{1}{L_{\mathrm{s}}} \cdot v_{\mathrm{s}}-\frac{1}{L_{\mathrm{s}}} \cdot e_{\mathrm{s}}-\frac{R_{\mathrm{s}}}{L_{\mathrm{s}}} \cdot i_{\mathrm{s}} \\
e_{\mathrm{s}}=C_{\mathrm{emk}}(\delta) \cdot \omega \\
J \cdot \frac{\mathrm{d} \omega}{\mathrm{d} t}=C_{T}(\delta) \cdot i_{\mathrm{s}}-f_{\mathrm{v}} \cdot \omega-T_{\text {load }}
\end{array}\right.
$$

\section{Linear Model}

Figure 6: Simulative test set-up

\section{Linear modeling of a Hybrid Stepping Motor}

Based on the nonlinear model, the phase currents and voltages can be transformed to a reference frame fixed to the stator current vector $\overrightarrow{i_{\mathrm{s}}}$.

For this transformation, the rotor position $\theta$ has to be known. Sensorless algorithms are able to provide this position information. [4]

If $L_{\mathrm{a}}=L_{\mathrm{b}}=$ Cte and $R_{\mathrm{a}}=R_{\mathrm{b}}=$ Cte then $L_{\mathrm{s}}=L_{\mathrm{a}}=L_{\mathrm{b}}$ and $R_{\mathrm{s}}=R_{\mathrm{a}}=R_{\mathrm{b}}$.

\begin{tabular}{|c|c|c|}
\hline Symbol & Parameter & Value \\
\hline$u_{\mathrm{a}}, u_{\mathrm{b}}[\mathrm{V}]$ & Motor phase voltage & \\
\hline$i_{\mathrm{a}}, i_{\mathrm{b}}[\mathrm{A}]$ & Motor phase currents & \\
\hline$R_{\mathrm{a}}, R_{\mathrm{b}}[\Omega]$ & Motor phase resistance & 0,5 \\
\hline$L_{\mathrm{a}}, L_{\mathrm{b}}[\mathrm{H}]$ & Motor phase inductance & 0,001 \\
\hline$K_{\mathrm{m}}[\mathrm{Nm} / \mathrm{A}]$ & Motor torque constant & 0,16 \\
\hline$e[\mathrm{~V}]$ & Back emf & \\
\hline$\omega[\mathrm{rad} / \mathrm{s}]$ & Angular velocity & \\
\hline$T_{\mathrm{c}}[\mathrm{Nm}]$ & Coulomb friction & \\
\hline$T_{\underline{\mathrm{v}}}[\mathrm{Nm}]$ & Viscosity friction & \\
\hline$f_{\mathrm{v}}[\mathrm{Nms} / \mathrm{rad}]$ & Viscosity friction coefficient & 0,004 \\
\hline$T_{\text {motor }}[\mathrm{Nm}]$ & $\begin{array}{c}\text { Torque generated by the } \\
\text { motor }\end{array}$ & \\
\hline$p$ & Number of pole pairs & 50 \\
\hline$I_{\max }[\mathrm{A}]$ & Maximum phase current & 4,7 \\
\hline
\end{tabular}
During vector control operation the load angle $\delta$ is controlled to be constant. Assuming a constant angle $\delta$, the model gained in figure $6-$ is linear as well as time-invariant.

\section{Model validation}

Table 1: Simulation Parameters

Simulations on a two phase hybrid stepping motor are conducted to validate the model as shown in Fig. 7. Both a detailed nonlinear and the linear model are used to represent a stepping motor. A hysteresis algorithm is used to control the currents.

The parameters used for the simulation are summarized in table 1, and are based on a real existing hybrid stepping motor. The simulation models are both controlled by a vectorcontrol algorithm in order to maintain constant speed. At the end of the simulation, the relative position deviation $\Delta \theta$ between the rotor position is computed, where:

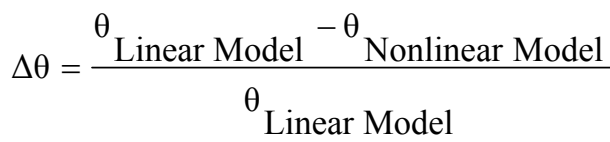

To simulate dynamical behavior, the speed set point is reversed at half the simulation time. Figure 8 illustrates that the rotor position deviation is always very small and is not correlated to speed or load torque. The maximum deviation between linear -and nonlinear model is only $0,025 \%$.

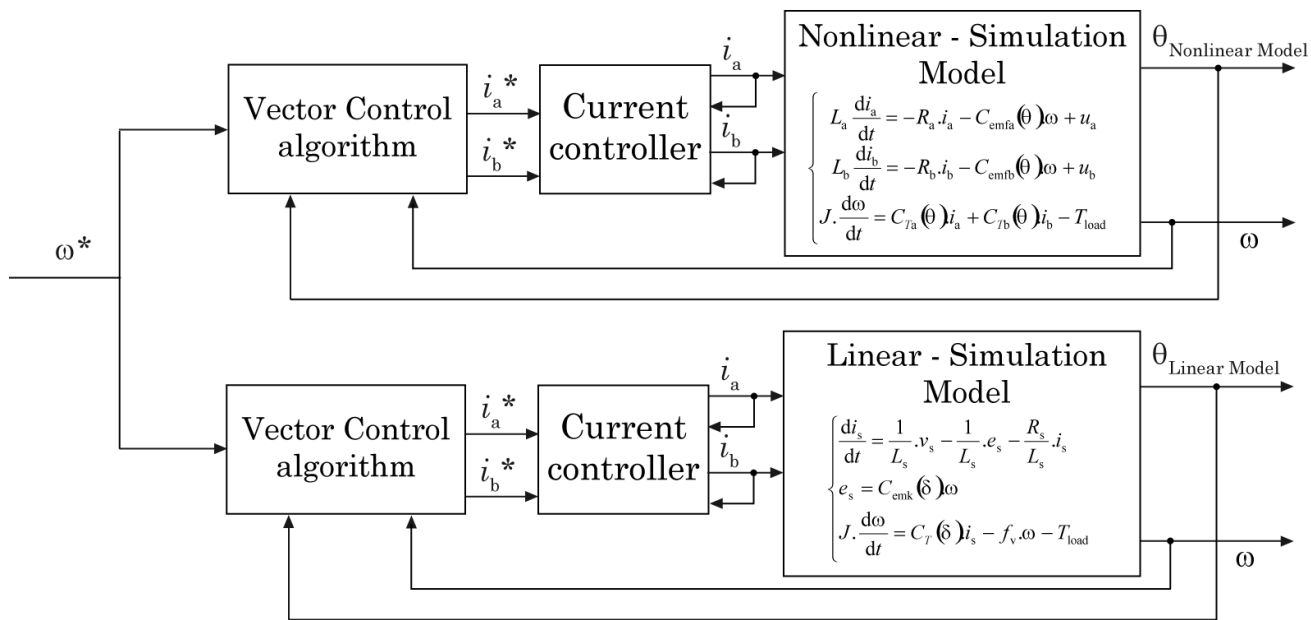

Figure 7: Simulation test set-up 


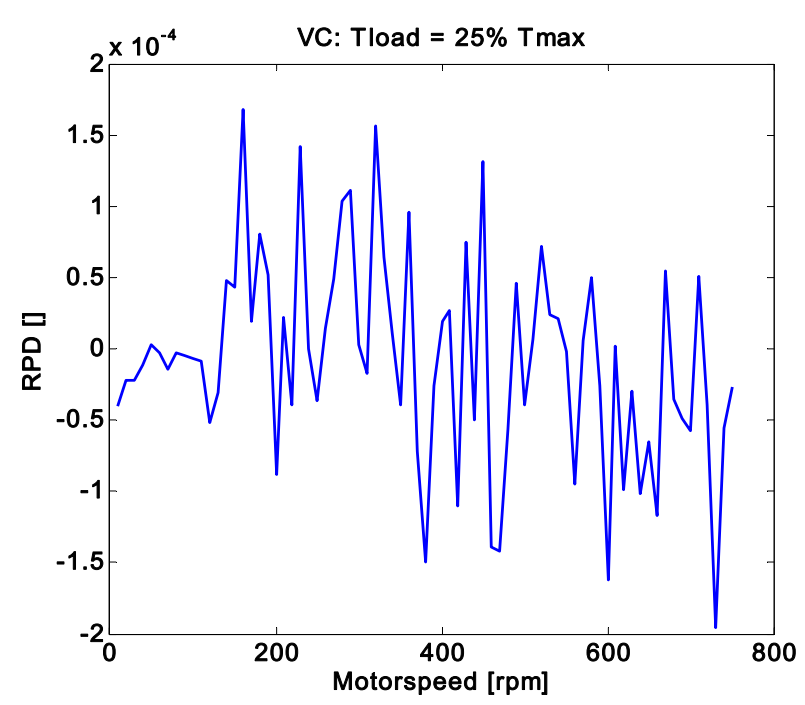

$a$

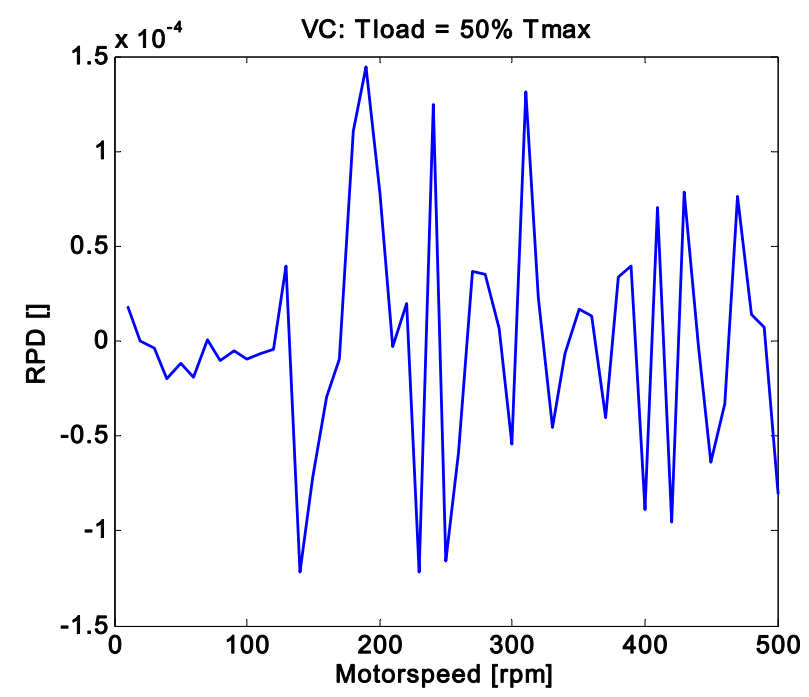

$b$

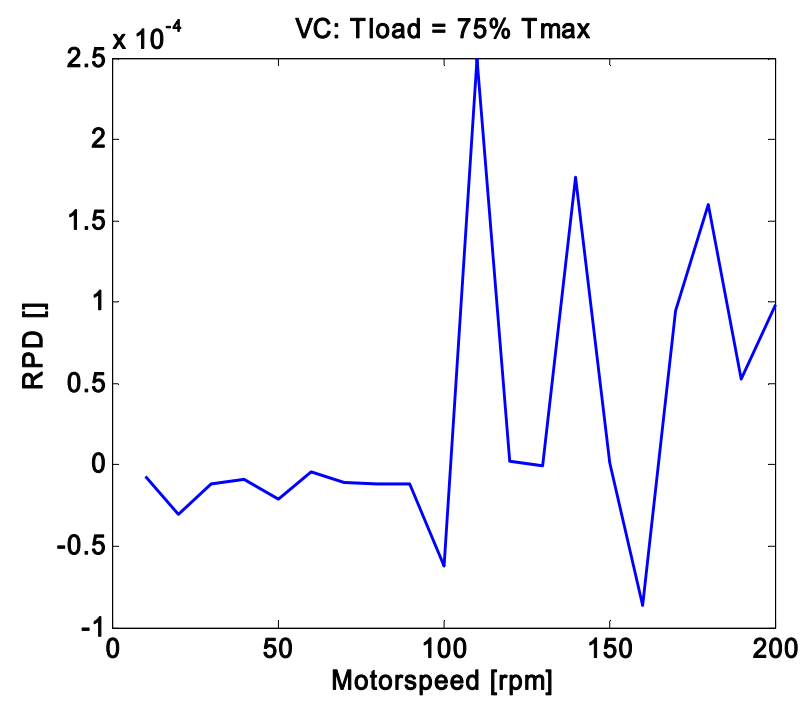

c

Figure 8: Relative position deviation (RPD) for different load torques and motor speeds.

(reversed speed set point at half simulation time)

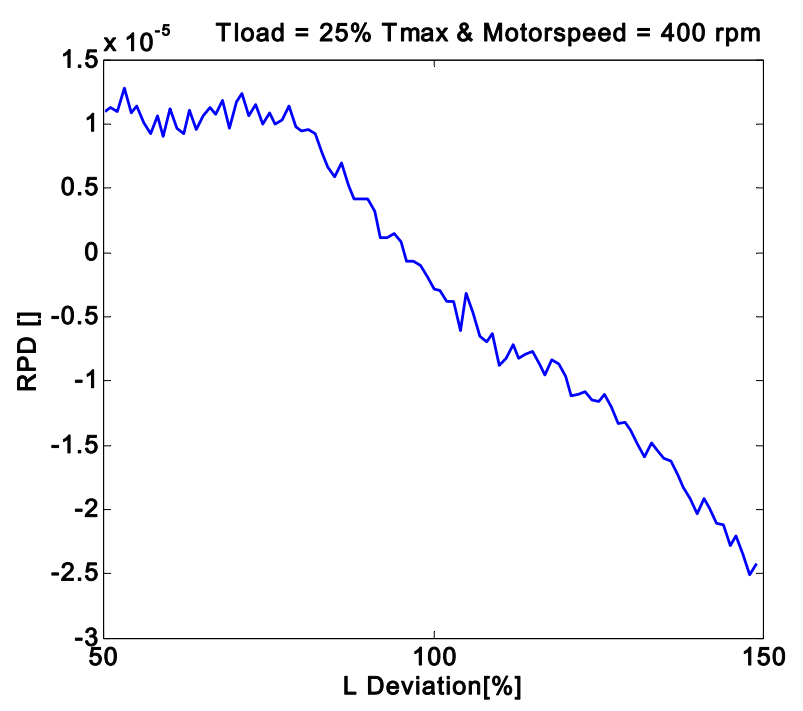

Figure 9: Sensitivity for $L$ deviation

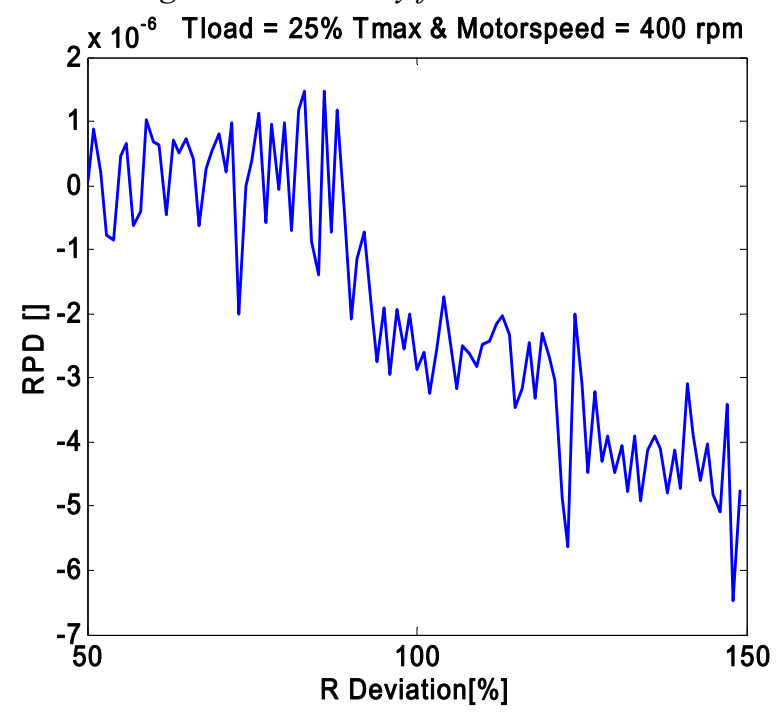

Figure 10: Sensitivity for $R$ deviation

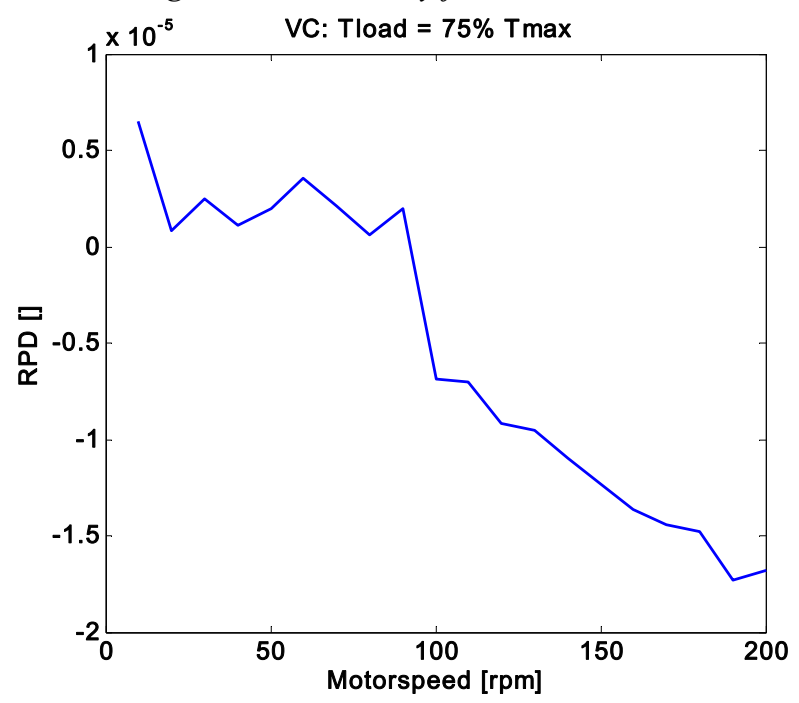

Figure 11: Sensitivity for rotor-position influence on $L$ 


\section{Sensitivity analysis}

To linearize the model it is assumed that $L_{\mathrm{a}}=L_{\mathrm{b}}=$ Cte. However, the inductivity can be influenced by the rotor position and saturation effects. Therefore the simulation setup is also used to execute a sensitivity analysis.

Figure 9 shows the relative position deviation (RPD) when there is a difference in inductivity for the linear -and nonlinear model. As shown in figure 10 the deviation is still tolerable when a wrong inductivity is proposed for the linearized model. When the estimated inductivity, used in the linear model is $150 \%$ of the real inductivity used in the nonlinear model, according to Fig. 9 the relative position deviation will only be $0,0025 \%$

In the same way a sensitivity analysis for the value of the resistance $\mathrm{R}$ is performed, resulting in Fig. 10.

Finally the non-linear model is adapted so that the inductivity $\mathrm{L}$ varies with the rotor position as illustrated in Fig. 12. As shown in Fig. 11 the maximum relative position deviation is $0,0006 \%$.

All these consecutive sensitivity analysis proves the robustness of the linear model.

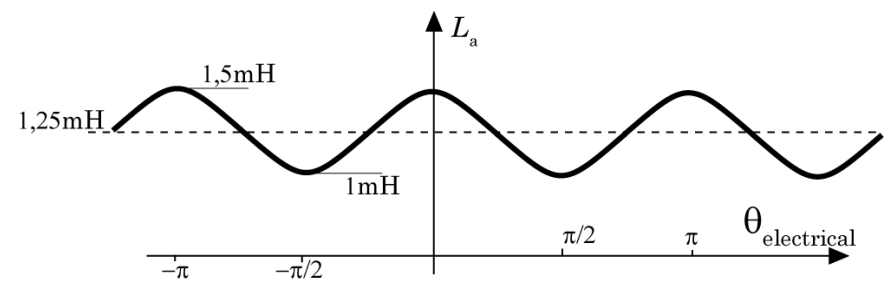

Figure 12: Inductivity L variation with rotor position

\section{Conclusions}

Based on the knowledge of vector control principles a linear model for a hybrid stepping motor is proposed. This model is validated by numerous simulations. Together with a sensitivity analysis these results show that the linear model is a very good approach when the stepping motor is controlled by a vector control algorithm. The model can be used for numerous applications such as linear observer algorithms for sensorless control. In many cases a linear model will be able to reduce the computational cost.

\section{References}

[1] WEIJI, L. AND ZHUO, Z., 2006. Simulation and Experiment of Sensorless Direct Torque Control of Hybrid Stepping Motor Based on DSP. Proceedings of the 2006 IEEE International Conference on Mechatronics and Automation p. 2133-2138.

[2] TOMPEI, P. AND VERRELLI, C. M., 2008. A nonlinear adaptive speed tracking, control for sensorless permanent magnet step motors with unknown load torque. International Journal of Adaptive Control and Signal Processing, vol. 22(3), p. 266-288

[3] HIDA, H., TOMIGASHI, Y. AND KISHIMOTO, K., 2007. Novel Sensorless Control of PM Synchronous
Motors Based on Maximum Torque control Frame, in Proc. of EPE2007 Conference

[4] PERSSON, J. AND PERRIARD, Y., 2003. Steady state Kalman filtering for sensorless control of hybrid stepper motors. IEEE International Electric Machines and Drives Conference, vol. 2, p. 1174-1177

[5] C. KUERT, et al., 2002. "New method for dynamic modeling of hybrid stepping motors," in Conference Record of the Industry Applications Conference / 37th IAS Annual Meeting., pp. 6-12 vol.1. 